\title{
Storytelling: An alternative home delivery of English vocabulary for preschoolers during COVID-19's lockdown in southern Thailand
}

\begin{tabular}{|c|c|}
\hline \multicolumn{2}{|c|}{$\begin{array}{l}\text { Authors: } \\
\text { Attawat Khamsuk }{ }^{1} \text { @ } \\
\text { Wararat Whanchit }^{1} \text { @ }\end{array}$} \\
\hline \multicolumn{2}{|c|}{$\begin{array}{l}\text { Affiliations: } \\
{ }^{1} \text { Department of English, } \\
\text { School of Liberal Arts, } \\
\text { Walailak University, } \\
\text { Tha Sala, Nakhon Si } \\
\text { Thammarat, Thailand }\end{array}$} \\
\hline \multicolumn{2}{|c|}{$\begin{array}{l}\text { Corresponding author: } \\
\text { Wararat Whanchit, } \\
\text { wwararat@mail.wu.ac.th }\end{array}$} \\
\hline \multicolumn{2}{|c|}{$\begin{array}{l}\text { Dates: } \\
\text { Received: } 28 \text { June } 2020 \\
\text { Accepted: } 05 \text { Jan. } 2021 \\
\text { Published: } 17 \text { Feb. } 2021\end{array}$} \\
\hline \multicolumn{2}{|c|}{$\begin{array}{l}\text { How to cite this article: } \\
\text { Khamsuk, A. \& Whanchit, W., } \\
\text { 2021, 'Storytelling: An } \\
\text { alternative home delivery of } \\
\text { English vocabulary for } \\
\text { preschoolers during } \\
\text { COVID-19's lockdown in } \\
\text { southern Thailand', South } \\
\text { African Journal of Childhood } \\
\text { Education } 11(1) \text {, a897. } \\
\text { https://doi.org/10.4102/ } \\
\text { sajce.v11i1.897 }\end{array}$} \\
\hline \multicolumn{2}{|c|}{$\begin{array}{l}\text { Copyright: } \\
\text { (c) 2021. The Authors. } \\
\text { Licensee: AOSIS. This w } \\
\text { is licensed under the } \\
\text { Creative Commons } \\
\text { Attribution License. }\end{array}$} \\
\hline \multicolumn{2}{|c|}{ Read online: } \\
\hline 口ria & $\begin{array}{l}\text { Scan this QR } \\
\text { code with your } \\
\text { smart phone or } \\
\text { mobile device } \\
\text { to read online. }\end{array}$ \\
\hline
\end{tabular}

Background: Storytelling, a common family activity for preschool children to develop their literacy, can be used to promote learning of a language other than the mother-tongue, hence a starting point of home education for early childhood.

Aim: The study aims to integrate storytelling as a family activity that helps to promote learning of English vocabulary for preschoolers.

Setting: Young children aged 3-5 years and their parents living in a small neighbourhood of Muang District, province of Suratthani, in the south of Thailand attended the study during the restriction imposed to curb the coronavirus disease 2019 (COVID-19) pandemic under the 'Stay at Home' measures (March-April 2020). Both parents and children were given information about the study before they decided whether or not to participate in the project by parents' informed consent for their child to be involved.

Methods: The data were collected in four stages: pretest, storytelling, post-test and interview. The storytelling material included five stories, particularly composed for the study. These stories were written in Thai (average 423 words), each with three English words inserted, making up 15 English words as the test items. Analyses were conducted on the pre- and posttest scores, observation of children's learning performance and parents' reflection.

Results: The preschoolers showed vocabulary development from listening to the in-house stories. On average, children obtained 12.2 scores out of 15 words in the post-test versus 8 scores in the pretest. The family's satisfaction level was high, that is, 3.5 from 4 on children's learning behaviour and English word development and 3.77 on stories appreciation. The preschoolers requested to hear a story as many as three times in order to be confident. The high frequency of hearing tended to predict individual's development.

Conclusion: Storytelling promoted English vocabulary learning and it could be done at home, provided that parents are equipped with appropriate material. In a story, preschoolers should be introduced to mono-syllabic concrete words and only up to three words at a time. Repetition of at least three times is necessary.

Keywords: COVID-19; English vocabulary; home education; preschooler; storytelling; Thailand.

\section{Introduction}

In Thailand, English is learned as a major foreign language and is included in the national curriculum as a compulsory subject for all school children. However, to master the language is quite a big challenge for children who have limited exposure. Likewise, for the teachers to prepare effective learning environments that enhance language acquisition is not an easy task. The low achievement amongst Thai students may be reflected in the relatively low English language test scores amongst all grade levels, as evidenced in the annual national tests. The official website of the National Institute of Educational Testing Service (NIETS) has reported the test results from the academic year 2019, stating that the primary school students (Grade 6) had an average score of $34.42 \%$ with an average of $45.95 \%$ amongst schools in Bangkok. The report also shows that school location has a strong correlation with the scores. That is, students from urban schools accomplished a higher average score than those in rural schools, that is, scoring $40.55 \%$ and $31.42 \%$, respectively (NIETS website n.d.).

As English education hssas been placed as one of the national agendas, important to the country's economic growth, the governments have launched policies and strategies to promote the use of 
English. For example, more schools offer English programme or Bilingual programme, higher education offers International programmes of study and all schools are urged to conform to the Roadmap for Education Reforms (Kaur, Young \& Kirkpatrick 2016). Training courses for regional teachers are provided throughout the country, but it was found that the knowledge gained may not be fully applicable for classroom practice in local primary schools (Sunyakul \& Teo 2020). Based on Sunyakul and Teo (2020), primary school teachers who have attended the Boot Camp (run by the British Council) for professional development admitted to not having a solid foundation in speaking and listening skills themselves, which impeded communicative teaching performance. Whilst high quality school teachers cluster in urban schools, some rural schools in a remote region may rather suffer finding teachers with strong academic strength in teaching English as a foreign language, and this may in some way affect students' ability in using English (Noomura 2013).

With the given challenges in English education in Thailand, it would sound unfair to believe that English knowledge could only be developed from formal education or that a family should completely rely on school teachers to provide their children with English knowledge. As the idea that primary literacy development should be cultured from home is a universal concept (Sibanda \& Kajee 2019), a practical way would be that the family supports their children's development of English skills even before they attend formal education. As the basic words for early childhood are simple ones and probably most educated parents would have acquired those words, it is within reach for them to play a role in educating their children.

After all, children are much cared for by their parents thus, implementing family centred intervention is a highly effective way to support young children's development (Kaiser \& Hancock 2003) and at the same time enhances parent-child bonding, as commonly known. An ideal family would normally be well-equipped with resources for child development, but it is well understood that a large number of parents in Thailand, especially in rural areas or in lowincome families, may not have enough resources or background knowledge to promote intellectual development to their children, especially when it comes to English learning (Schaefer \& Kotzé 2019).

Amongst many challenges in language learning, knowledge of vocabulary seemingly stands out as a major concern because it directly impacts the desire to communicate. That is, not knowing the word meaning is more likely to obstruct communication than not knowing the grammar (Wilkins 1972). For early childhood development, growing vocabulary strength is essential for literacy in both home-language and a foreign language. As strong vocabulary is strongly related to childhood development of literacy (Roskos, Burstein \& Sullivan 2013), vocabulary is recognised for its importance as 'the core' of language comprehension, which earns vocabulary a priority in preschool language and literacy programmes. Despite such broadly accepted view, families and schools at large still struggle to find effective ways for vocabulary learning. As Neuman and Dwyer (2009) maintained, appropriate strategies and activities pertaining to vocabulary development in young children are much needed, and it is also advisable to strengthen vocabulary from early childhood as this helps scaffold literacy to further strengthen the child's competency.

The strong relationship of English to economic growth and the priority given to Thai citizens' English proficiency despite limited exposure to English as only a foreign language in Thailand, urged the need for parents and educators to implement strategies and means to support English language learning. For instance, a lot of parents would start teaching English to their children through speaking or calling things in English to encourage them to learn English language as an extra language besides their home language. Other parents may employ stories to engage young children with contextualised meaning during which they develop the 'mentalese' process (Cameron 2001). When performed in the child's early development period, telling stories or reading stories to children will help scaffold their knowledge and increase creativity (Gallets 2005; Phillips 2000). For parents with sufficient background of English, direct instruction may be the most accessible method. However, some parents may be concerned over their own language and phonological skills, which correlate the child's literacy development (Puglisi et al. 2017). That is why a fairly large number of parents would rather encourage young children to take extra lessons of basic English from professionals or at tutorial schools, wishing to fulfil the need for a firm ground of English from childhood. No matter what attempts parents have made concerning the child's English learning, the overall goal is to develop literacy in the foreign language. Thanks to the active characteristics of very young learners, parents are advised to find various activities with hands-on experiences for the child to learn effectively (Uysal \& Yavuz 2015).

This study, therefore, was designed to promote English language learning of preschool children, so-called preschoolers (aged 3-5 years old), living in a small neighbourhood during the implemented lockdown measures because of COVID-19 pandemic. With no prior exposure to English, these preschoolers were expected to develop English vocabulary knowledge through storytelling activity under a hypothesis that an insertion of English words in a story told in Thai would develop English vocabulary knowledge, and hence result in vocabulary acquisition. Despite a common assumption that target language be used to teach a language (Cook 2019), this study maintains that the story would be properly narrated in the mother tongue, Thai, to accommodate their understanding (Uysal \& Yavuz 2015).

The study has formatted a research question as its central point: To what extent does storytelling with the insertion of English words promote preschoolers' vocabulary learning? The findings were expected to provide guidelines for teaching English words to preschool children and suggest an alternative for informal English education. The study would also reveal a 
feasible family activity to promote learning whilst family members are confined in their home as experienced worldwide during the lockdown. By visiting a family and introducing a story with English words inserted, the researchers could demonstrate both storytelling and English word pronunciation. Parents would be able to take part in their child's early learning of English in a very manageable way because it does not demand much of their prior knowledge. It should also be noted that the stories were intentionally composed for this study. No illustrations were available except for the separated pictures for the English words shown to students when the word was being introduced to reinforce the learning and perhaps acts as a prompt for parents.

\section{Objectives}

This study was set up with the following objectives:

- to develop guidelines for using storytelling as a homebased activity that enhances English vocabulary learning for preschoolers

- to provide English learning experience to young children during the nationwide lockdown measures against COVID-19 spread

- to persuade parents that storytelling is a feasible way to teach young children English vocabulary and it could be effectively conducted at home.

The study was, therefore, integrated as a social engagement project to benefit young children who were compelled to stay home according to the national lockdown measures. Presumably, this academic services project would directly benefit the children and bring positive results to the community and local education in the long run.

\section{Definition of terms}

Storytelling refers to an oral presentation of a story in which, by convention, a story would be recited or told from memory. However, in this study, the stories were not entirely remembered because of their new content, and the teller had to glance at the text whilst telling story.

Story reading refers to an oral presentation in which a storybook with illustrations is read aloud, most commonly, to children.

\section{Literature review}

Storytelling is considered as one of the oldest established forms of entertainment in all cultures. By nature, humans verbalise their thoughts and tell of what has happened as a basic way of communication. Stories may be told to entertain, to inform, to pass on cultural heritage or to warn of danger (Lugmayr et al. 2017). As universally agreed, most stories for children aim to instill virtues, thus the child is brought up as a human with morality and virtues. That is, probably why the Aesop's Tales, for instance, have been the world's classics for centuries and often used as anecdotes. For pedagogical application, storytelling is one way to transfer knowledge to children about the world around them (Phillips 2000). Listening to a story is like a simulation of the world being brought to the child's comfort zone. Whilst a child may be raised in a small neighbourhood, stories can introduce the world beyond reality and open up the child's imagination, as well as experience through words. On top of that storybooks are likely to contain references to human mental states from which children can learn the different personalities through characters (Farkas et al. 2020). With adult's guidance whilst telling story, the child can develop both literacy and comprehension of the world around them.

Stories to be told to young children come from different sources and are categorised in different ways, usually based on the themes, with fairy tale, myth, animal tale, jest tale and legend as the most conventional ones (Bunparit 2014). Ellis and Brewster (2014) suggested that storybooks may be taken from children's literature and could be adapted or retold with a humorous twist whilst some are taken from everyday stories, fantasy stories, animal stories or stories existing in one's own culture.

Nevertheless, on surveying the storybook market these days, one would also notice a wide variety of newly written stories related to children's everyday life and world knowledge. These stories are on the rise as they connect children with morals or virtues in the modern world and contemporary content. For example, a story illustrates a child's daily routine to highlight the importance of self-care and responsibility. If appropriate guidance is given, the child's awareness will be raised. The wider and more diverse story choices mean the stronger the need to select appropriate ones to meet the child's need. Parents, teachers or users will have to adapt the plan if the chosen story does not appear appealing to the children as anticipated (Ellis \& Brewster 2014).

It should also be noted that studies of storytelling may approach the activity in two ways. For one, it refers to the act of adults telling a story to (usually) young listeners. For the other, storytelling involves children's development of literacy and language by telling stories themselves. This review focuses mainly on adults telling story to children with some extension to story being read to children because the latter shares some features to the former one. They both received reputation for their benefits to young children in various aspects (Gallets 2005).

Storytelling has benefited development of child's literacy and has long been praised as an effective method for communication skills development. Roney (1996), for instance, posited that storytelling activity engages the child in 'whole-brain' education. To him, participation in storytelling actively engages both the teller and the listener in a meaningful language experience (Roney 1996). Also, Matthew James Friday (undated retrieved 2020) elaborated 'How storytelling inspires children to learn English' on the website Kurzweil Education, which has sparked the idea and inspired the design of this study. 
In the classroom setting, stories are usually told to serve various purposes - to develop literacy, to build comprehension skills, to teach morality, to entertain, to promote creativity, to introduce a cultural aspect and to teach a language. However, when conducting storytelling activities, the teacher needs to take a few factors into consideration, such as the criteria in selecting stories that easily connect with the students' experience (Ellis \& Brewster 2014). For a teacher to successfully tell the chosen story, Ellis and Brewster (2014) maintained the necessity of prepared materials, which can be books, illustration, media, arts, pictures, story props or puppets. For early childhood, studies have shown that illustration is a good aid to engage them with the activity (Phillips 2000) and enhance virtual skills (Ellis \& Brewster 2014). If the teacher has merely an oral presentation, it is important to take control by using mime, gesture, facial expression and sound effects whilst telling a story, especially when dealing with a group of young pupils (Ellis \& Brewster 2014). As Phillips (2000) posited, when a story is well-told, the young children, who are by nature interested and enthusiastic towards told stories, will develop and extend skills and knowledge. Furthermore, the use of gestures can even result in improving the child's production of narrative discourse performance (VilàGiménez, Igualada \& Prieto 2019).

Another factor contributing to success of storytelling is the use of media, particularly at the present time when access to computers and electronic devices such as smartphones and tablets has been made much easier. Whilst multimedia technology can highly support learning and meet the need to keep the children interested in listening to the story, the teacher needs to be capable of choosing the right methods to enhance motivation (Robin 2008).

Effectiveness of storytelling has been widely explored in diverse contexts, contributing to establishing a strong ground for storytelling activity in early childhood education. One prominent feature of storytelling is its promotion of morality. A mixed-approach study conducted by Soommanus and Musikaphan (2019) compared the moral behaviour of 69 early childhood students in child development centers in the province of Ranong, Thailand before and after using storybased activities. Positive results were revealed in quantitative data on moral behaviour scores, which were for 'self-control', 'kindness' and 'self-reliance', respectively. The qualitative data of interview elicited five ways to promote moral behaviours. Specifically, teachers and parents may raise questions that challenge the child's thinking, offer a reward and give punishment when necessary, consistently repeat the content, act as role model and set up an agreement with the kids.

Making use of the classic Aesop's Tales in English, Thanompongchart (2019) conducted a study on primary school students in Grades 4-5 to develop English competency and inculcate virtues. She found the mean scores of English achievements and moral higher in the post-test than the pretest. Even though the experiment group did not significantly outperform the control group, their English achievement test scores were slightly higher.

The study concluded that the Aesop's Tales tended to influence the students on honesty, kindness, gratitude and sacrifice.

Likewise, Balakrishnan and Thambu (2017) used case studies for qualitative data from seven preschoolers of mixed-ethnic groups (Malay, Indian, Arabic). The children showed positive attitudes towards the use of storytelling, and they could transfer the moral from the stories to their own lives. It was then concluded that storytelling is an effective learning tool for children, given that the story is told in interactive ways and promote learner's engagement.

Apart from moral education, studies also confirm the great benefits of storytelling on language development and literacy in early childhood. For example, McKeough et al. (2008) proposed a literacy programme to support the aboriginal children's development in Canada. Based on the census, these indigenous people in the boundaries of Canada were reported to have low literacy rate in comparison with other Canadians. Reasons for the low performance were identified as poverty, health issues, language challenges, cultural factors and limited literacy education. However, as the ethnic groups had their oral narrative tradition, the study proved storytelling to be an effective way to engage the young learners in learning to verbalise narrative stories; hence appropriately supporting literacy development. For example, the use of conjunctive words was introduced to these young aboriginal children and scaffolded their learning towards telling cohesive stories using the English conjunctive words by themselves.

A European researcher, Kirsch (2012), investigated the use of storytelling in German classrooms for primary students and asserted that storytelling results in vocabulary acquisition and retention. Likewise, in Asia, Srihasarn and Wuttipornpong (2013) compared the two methods used for vocabulary enhancement in Grade 7 students (Mattayom 1 in the secondary level of Thailand's formal education system) in a secondary school in Amnatcharoen Province, northeastern Thailand. Whilst one group of participants went through storytelling mode, the other learned by memorising words as in a conventional classroom. The finding suggests that both ways helped the learners significantly acquire new words, with the storytelling group greatly outperforming the memorising group in the post-test. As the storytelling activity involves discussion and writing up after listening to the story, the group with storytelling treatment could better retain the vocabulary knowledge.

Collins (2010) investigated the vocabulary acquisition from storybook reading amongst preschoolers in two groups, one with rich explanations of vocabulary and one without. These children were non-native speakers of English, listening to eight commercial storybooks with five to nine target vocabulary words insertion in each book. 
Findings revealed that $33 \%$ of the new words were acquired after hearing the words in context, but the acquisition increased to $50 \%$ by a company of rich definitions. This study also reported that frequency of reading at home (with parent's support) was a significant predictor of target vocabulary test score. In line with Collins (2010), a study by Roskos et al. (2013) gave a quite similar finding that increasing frequency of intervention leads to improving vocabulary acquisition amongst preschoolers with vocabulary delays. This has a positive implication that if the learners are given more intensive exposure to the target vocabulary by the approach 'more of the same', they will eventually attain the vocabulary.

A more recent study was conducted by Vaahtoranta et al. (2019) in an attempt to find appropriate strategies in teaching vocabulary to preschoolers. To them, vocabulary development was perceived as important to develop from early childhood, thus they designed shared reading activities to foster word learning based on the approaches developed in Vaahtoranta et al. (2018). The study set up three English language environments involving shared reading activities with 126 preschoolers in five kindergarten schools in southern Germany. In the first group, the interventions included interactive elaborative storytelling in which the stories were read aloud and words learning techniques were introduced. Then, the children were asked to continue the story, and later retell the story they had heard. The second group attended elaborative storytelling in which a story was read aloud and the word learning techniques were taught. Then, the children were asked to continue story, but without retelling it. The third group received a read-aloud intervention. In this group, students listened to stories, but were not taught the word learning techniques nor asked to retell the story. However, the intervention included phonology awareness and word games. The results show a significant level of vocabulary gain in all experimental groups. However, word gains amongst the groups did not differ even though the expectation had been that the interactive elaborative storytelling would benefit more.

On the other hand, elaborative storytelling provides the children with more contextual information and without explicitly teaching the words. The learner would understand the words from context. Children are guided by rhetorical questions, detailed elaboration and the use of synonyms. Words chosen as targeted learning were based on criteria employed in a study by Vaahtoranta et al. (2018), with a low frequency of occurrence in everyday communication and in children's books. With the focus placed on the story and children being attentive, the children would incidentally gain the words.

\section{Methodology \\ Setting}

With the precautious measures requesting citizens to stay at home to curb the pandemic of the coronavirus disease 2019 or COVID-19, children remained at home as schools were cancelled. One of the researchers visited nine local families in Muang District of Suratthani Province in southern Thailand in order to conduct the study aiming to train English vocabulary words to nine preschoolers via storytelling in Thai with English words inserted. Parents were asked to be present whilst stories were told so that they could make use of the material later after the experiment. The data collection process spanned a 2-week period.

\section{Hypothesis}

This study hypothesised that preschoolers could be introduced to English words inserted in stories told in Thai. They were expected to remember the words after hearing the storytelling with English words in context explicitly taught.

\section{Research participants}

Purposive sampling criteria for recruitment were used to select participants regardless of prior English vocabulary knowledge. Nine native Thai children, living in the same neighbourhood in Surat Thani Province in the south of Thailand, aged 3-5 years, agreed to take part in the study as research participants, all with consent from their parents. None had any experience participating in research. The participants and parents were informed of the request for cooperation concerning the purpose of the study, period of the training, conditions of the training and overall procedure, the potential effects, the benefits, as well as the ability to quit the programme at any time before giving consent.

As part of the protocol to keep identity confidential, the participants were assigned specific pseudonyms throughout, as detailed in Table 1 .

\section{Research design}

The researcher told each story to the children with reference to the written script in Thai. Voice and tones were adjusted to match the characters. Each story was told twice as the higher frequency of storytelling means a more positive effect on the listener (Collins 2010; Roskos et al. 2013). Storytelling may be repeated upon the child's request. The inserted English words were mentioned in context of the story. When introducing the word, the researcher showed a corresponding picture and pronounced the word in English before urging the child to repeat the word. This pronunciation training was

\begin{tabular}{llcc}
\multicolumn{2}{l}{ TABLE 1: Participants' information. } & & \\
\hline No. & Identity & Sex & Age (year) \\
\hline 1 & Child A & M & 5 \\
2 & Child B & F & 4 \\
3 & Child C & M & 3 \\
4 & Child D & F & 4 \\
5 & Child E & F & 5 \\
6 & Child F & M & 5 \\
7 & Child G & F & 4 \\
8 & Child H & M & 3 \\
9 & Child I & M & 3 \\
\hline M, male; F, female. & & &
\end{tabular}


meant to familiarise the child with the word associated with the picture. Each word was repeated three times and could be extended to four times depending on the child's demand. After the storytelling stage, the child's vocabulary acquisition was checked. For this, the researcher said the target word and the child would select a corresponding picture; the answers were recorded. This design is suitable for young children who are unable to read. The researcher observed and took note of the child's behaviours whilst listening to stories and the storytelling atmosphere. After the activity, the child's parents were requested to assess the child's development and report it on a given evaluation sheet.

\section{Data collection procedures}

All nine participants were at their own home with their parents or guardians whilst the researcher visited each of them for data collection. Note that as a precaution to the COVID-19, the researcher wore a mask at all time during the visit. He first had a general conversation with the family to put the children at ease. Some children were present in a group whilst some others individually joined the storytelling programme.

As the study aimed to examine the treatment effects of storytelling on target vocabulary acquisition in preschoolers, the participants were firstly tested for their knowledge of the target words. This pretest was conducted by the researcher saying the word in English and asking the child to identify a matching picture.

Scores were recorded to represent individual's performance before the beginning of storytelling session. At this point, the researcher encouraged the parent to join the session to keep the child at ease and to demonstrate to parents the use of story with English word pronunciation.

Next, the researcher told a story twice, each time taking up to $5 \mathrm{~min}$. As the child's request for an extra round was possible, the number of times a story being told was also recorded in order to identify how much exposure would be needed for the preschoolers to acquire the target vocabulary. The English words were intentionally taught with meaning in context, with a repetition of at least three times. The child was guided through pronunciation practice. After the story was repeated and ended, the child was asked to do the post-test, which was similar to the pretest. That is, each word was called out by the researcher and the participant selected a corresponding picture. The answers were recorded for assessment on the developmental level of individual's vocabulary acquisition. The procedures were repeated until all five stories were told and all data were collected. An interval between each story lasted 3-5-min.

\section{Research instruments}

The project employed four main instruments for data collection: five stories, a pretest and a post-test, parent's evaluation sheet with an informal interview and researcher's observation note.

\section{Five stories}

A total of 10 stories were originally composed in Thai to match the chosen topics in an accredited local nursery school's curriculum (Chumchon Mai Community Child Care Center, Thasala District, Province of Nakhon Si Thammarat, in the south of Thailand). Five stories were selected for the study under the criteria of attainable words for nursery level. The story has an average of 423 words (ranging from 353 to 526 words in all five). The titles include Diligent Little Ant, Forest, Joyful Little Bird, Our Livable World and Finding Butterflies.

The five stories were modified with insertions of three English words in each story, making a total of 15 words to learn. These selected words were mainly related to storylines, regardless of their parts of speech, but all were lexical words (no functional words). The content involves world knowledge of animals and insects existing in nature, such as the butterfly, bird and ant. It should be noted that the newly created stories were meant to support learning amongst young learners in nursery school and were composed to relate to the young learners in rural areas who were highly exposed to the world of nature. The reasons for using newly invented stories were that such relevant content would be accessible and connecting to the lessons that young children were required to learn. The goal was the learner's development of skills such as naming things, basic English word recognition and the virtues integrated into the plot.

The English words for the preschoolers targeted for learning outcome are listed here:

- Diligent Little Ant: ant, two, red

- Forest: tree, walk, green

- Joyful Little Bird: bird, nest, apple

- Our Livable World: the sea, the sun, hot

- Finding Butterflies: butterfly, fly, leaves

A limit of three English words for each story would not overwhelm the children. As suggested in Sightwords.com (a website for resources to teach reading to young children), young children would better recognise a few words accurately and develop a solid knowledge than having sighted or heard so many and only vaguely having recognised them.

\section{Pretest and post-test}

The pretest and post-test were identical and designed to check the participant's acquisition of the English words introduced in each story. They contained 15 words all together. The participants were administered a pretest and a post-test, conducted orally before and after each story was told. Each test lasted 3-5 min, thus the children would not be overstrained. Whilst testing, the participants went through the same process as the story delivery steps. Participants were asked to listen to the uttered English word and match the word with a correct picture. The post-test aims to test their word memory and retention. 


\section{Parent's evaluation sheet with an informal interview}

Parents were given an evaluation sheet to assess their child's development of vocabulary after listening to the story. The questionnaire contains 15 items, divided into three sections of evaluation criteria: content, English vocabulary and an element of entertainment. The evaluation came along with an informal interview for clarification and in-depth information. Parents' insights were presumably reflecting the child's background and existing knowledge before joining the project, and they would recognise the child's improvement. This process took place at the end of all activities with the children.

\section{Observation note}

Whilst conducting the study, the researcher took notes of the child's behaviour, reactions and language performance. The observation began when the child entered the conversation and began the test until the end of all activities when all five stories were told.

\section{Data analysis}

The collected data on individual's performance before and after listening to each story were analysed for mean score to compare each participants' improvement. The scores were used to identify the immediate learning outcome. Responses are scored 0 or 1 (for incorrect and correct answer, respectively), for three items in each story, making up a maximum of 15 items from all five stories. Raw scores were used for the analysis.

Records of the number of times a word was repeated, which is referred to as 'number of hearing', were used for analysis of possible time required for preschoolers' immediate vocabulary acquisition. Results from the five stories were compared to identify level of word difficulty that may reveal some potential guidelines for English vocabulary selection to teach preschoolers in the same context.

The questionnaire and parents' interview results were content analysed and triangulated. Firstly, parents' evaluation focused on the stories for their content, selected vocabulary and elements of entertainment. Secondly, parents' opinions about storytelling activity were explored.

\section{Ethical consideration}

The involvement of children and parents in this study was done with total observance of informed consent and high confidentiality of the information maintained.

\section{Results and discussion}

Aiming to answer the research questions, 'To what extent does storytelling with the insertion of English words promote preschoolers' vocabulary learning?', this section reports the results and discusses the research outcome. The findings consist of four main sections: the children's performance, target words influence, the parents' evaluation of the project and other observed learning behaviours.

\section{Children's performance}

Based on the pre- and post-test scores of the children's ability to match the picture with the word they heard, Table 2 shows the score of correct answers by each participant. Of all 15 words from five stories, the average score was higher in the post-listening test $(12.22 / 15)$ than the average score before the learning (8/15). This may signify the preschoolers' vocabulary acquisition through storytelling inserted with English words.

As seen, Child A outperformed the others with almost a full score (14/15 points) probably because he was a year older and had been more exposed to English from online media encouraged by the parents. Interestingly, three children aged 3 years (Child C, H and I) and one aged 4 years (Child G) made a big improvement in their vocabulary learning.

The child's performance was further analysed in association with the frequency of story being told (the number of hearings) before the child was ready to take the test of vocabulary words learned from the story. Results in this part are presented in detail from all five stories, as shown in Table 3.

As seen from Table 3, the average of correct answers after listening to the story was higher than that in the pretest in all stories. The findings suggest two issues worth noting.

Firstly, the inserted words in Story number 4, Our Livable World, appeared as the least acquired; they were 'the sea', 'the sun' and 'hot'. As seen, whilst in other stories, the participants could score over two words, Story number 4 obtained less than two correct answers (1.67 from 3.00). As broadly agreed, children would begin learning single words, it is then likely that phrases consisting of a noun and a determiner were a challenge for them. Without grammatical explanation, the children relied only on memorising the phrase.

Secondly, data on the frequency of hearing a story in Table 3 tends to correlate the number of correct answers of each participant. This corresponds, for example, Al Zoubi (2018), Collins (2010) and Roskos et al. (2013), who maintained a positive impact of exposure to the target language on the learning outcome.

The frequency of hearing the story was then further ventured in relation to individual's performance by comparing the average score with the average frequency of hearing, shown in Table 4.

\begin{tabular}{|c|c|c|c|c|}
\hline No & Name & Sex (age) & Pre-listening $(n=15)$ & Post-listening $(n=15)$ \\
\hline 1 & Child A & M (5) & 12 & 14 \\
\hline 2 & Child B & $F(4)$ & 7 & 11 \\
\hline 3 & Child C & M (3) & 3 & 9 \\
\hline 4 & Child D & $F(4)$ & 8 & 13 \\
\hline 5 & Child E & $F(5)$ & 12 & 13 \\
\hline 6 & Child F & M (5) & 10 & 12 \\
\hline 7 & Child G & $F(4)$ & 6 & 12 \\
\hline 8 & Child $\mathrm{H}$ & M (3) & 7 & 13 \\
\hline$\underline{9}$ & Child I & $\mathrm{M}(3)$ & 7 & 13 \\
\hline \multicolumn{2}{|c|}{ Average } & & 8.00 & 12.22 \\
\hline
\end{tabular}

$M$, male; $F$, female. 


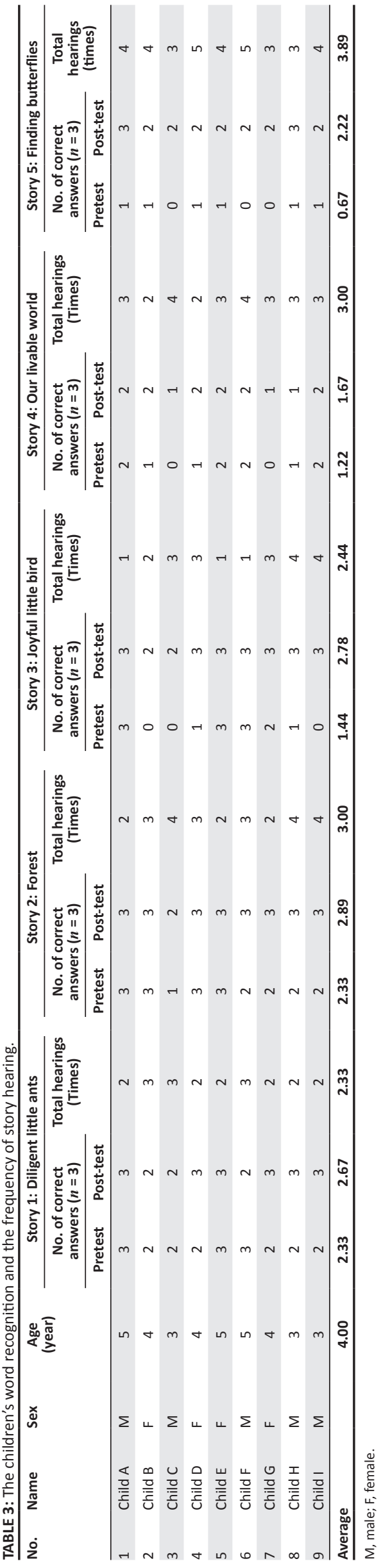

TABLE 4: Average score of tests and the number of hearing time.

\begin{tabular}{llccc}
\hline No. & $\begin{array}{l}\text { Participant's } \\
\text { identification } \\
\text { (sex/age) }\end{array}$ & \multicolumn{3}{c}{ Individual's average score $\dagger$} \\
\cline { 3 - 4 } & & $\begin{array}{c}\text { No. of correct answers* } \\
\text { Overall }\end{array}$ & $\begin{array}{c}\text { Overall } \\
\text { pre-listening } \\
\text { post-listening }\end{array}$ & \\
\hline 1 & Child A (M/5) & 2.4 & 2.8 & 2.4 \\
\hline 2 & Child B (F/4) & 1.4 & 2.2 & 2.8 \\
3 & Child C (M/3) & 0.6 & 1.8 & 3.4 \\
\hline 4 & Child D (F/4) & 1.6 & 2.6 & 3 \\
\hline 5 & Child E (F/5) & 2.4 & 2.6 & 2.4 \\
\hline 6 & Child F (M/5) & 2.0 & 2.4 & 3.2 \\
7 & Child G (F/4) & 1.2 & 2.4 & 2.6 \\
\hline 8 & Child H (M/3) & 1.4 & 2.6 & 3.2 \\
\hline 9 & Child I (M/3) & 1.4 & 2.6 & 3.4 \\
\hline Average & 1.6 & $\mathbf{2 . 4 4}$ & $\mathbf{2 . 9 3}$ \\
\hline
\end{tabular}

$M$, male; F, female.

$\dagger$, All 5 stories.

$\$, 3$ points.

Table 4 shows diverse performance amongst participants, with everyone improving. In general, the older the child was, the higher score was made. The average development of the children after listening to the story and learning words in context is higher $(2.44 / 3)$ than that before the listening $(1.6 / 3)$. As each child was allowed to hear a story upon their will or until they felt ready to test the word recognition ability, the number of hearing times varies. The average time, however, suggests that younger children were prone to request to hear a story as many as three times in order to be confident. The high frequency of hearing tended to predict individual's development.

Albeit being a different kind of language exposure (not such a common practice like doing a long-term activity), a story being told 2-4 times resulted in preschoolers' development of vocabulary in a short period of time, depending also on individual's motivation.

Considering individual's ability, we can see that Child A has the best performance. His pretest score is 2.4 and post-test is 2.8 on average. However, the vocabulary development is more obvious in Child G, Child C, Child H and Child I, who made over one-point higher score. Amongst these high achievers, the average hearing a story was over three times. For instance, Child H's average listening time was 3.2 and Child I's 3.4. with results improving from 1.4 points to 2.6 points for word recognition.

\section{Target words influence}

Another important issue that arose as influential to the children's performance was the stories and inserted English words. Based on the observation notes regarding the children's performance whilst listening to each story, this part discusses the words in relation to the children's performance.

\section{Story one: Diligent little ants}

Vocabulary: ant, red, two

Even though the words were new to most children, most could guess and choose a corresponding picture. 
Whilst the average pretest was 2.33 points (out of 3 ), the average post-test score was only slightly higher, 2.67. A difficulty the children faced was the word 'red', as the children admitted not having used or been introduced to the word.

\section{Story two: Forest}

Vocabulary: green, tree, walk

For Story two, the words 'walk', 'green' and 'tree' were well received by the learners. One of them, Child A, reported having learned the words in the nursery. The overall score for this story improved from 2.33 to 2.89 , which may indicate a satisfactory learning outcome. The word that children experienced difficulty remembering was the verb 'walk'. This may be attributed to its unusual pronunciation for the Thai learners, and such verbs would be better learned when coming along with an action, like in a total physical response (TPR) approach in which young learners show engagement and language development without explicit pressure (Shi 2018).

\section{Story three: Joyful little bird \\ Vocabulary: apple, bird, nest}

Amongst all stories, words in Story three were most likely unknown to the children before joining the project, as seen from the average 1.44 from 3 in the pretest score. After listening to the story, the children could recognise the words as the score increased up to 2.78 on average with seven children correctly matching all three words with their meaning after listening to the story. It could be speculated that the words 'apple', 'bird' and 'nest' (with 'nest' least acquired) are all nouns, and previous studies have shown evidence that nouns are easier to learn than verbs (Childers \& Tomasello 2006). The noun can be effectively introduced with the use of pictures, which has been noted as necessary for young children and especially preschoolers (e.g. Cameron 2001; Wright 1989; Xiaofei \& Modehiran 2019).

\section{Story four: Our liveable world}

Vocabulary: hot, the sea, the sun

Of all the five stories, the test from Story four yielded the lowest learning outcome. Whilst the average pretest score of 1.22 was improved to 1.67 in the post-test, no participants achieved three points for word recognition.

It is unclear why the three words were hardly attained despite the story being repeated up to 4 times. On closer examination, two of the targets in this story were phrases, containing a definite article 'the', a grammatical feature that does not exist in Thai. This may have contributed to the children's difficulty in memorising them.

Thus, it would have been less complicated if the words were introducing in their plain form, that is 'sea' and 'sun', instead.
In other words, teachers would need to be intentional with word selection (Neuman \& Wright 2019).

\section{Story five: Finding butterflies}

Vocabulary: butterfly, fly, leaves

Before listening to the story 'Finding Butterflies', the participants had very little knowledge of the three target words, accounted for 0.67 from 3 . The children improved greatly after listening to story for an average of nearly four times (3.89) in learning those words, as seen from the score of 2.22. This big gap in word acquisition tends to positively reflect storytelling as a method of learning vocabulary in context, given that the young learners have enough exposure to the target words. The notes also show children's difficulty with 'fly' and 'leaves', probably as a verb and a rarely used noun, respectively. Pronunciation of these two words was also found to be cumbersome for these 3-5 years-old children. The sound ' $v$ ', for example, is not used in Thai language sound system. The sound ' $\mathrm{v}$ ' is then transcribed as ' $\mathrm{w}$ ' sound in Thai. Thus, most novice users and young learners would replace it with ' $w$ ' a more common sound in Thai (Imsri 2015; Kanokpermpoon 2007).

In addition, because verbs are action word, teacher may act whilst introducing a verb in context to make the word more memorable (Lowry 2016).

Altogether, an individual's performance was likely to correlate with age. That is, children who could memorise new words within only 1-2 times of hearing the story were those aged 4-5 years. On the other hand, children aged 3 years would need to hear the word up to 3-4 times and listening to the story up to 3-4 times. A remark was also made whether or not the intervention was affected by the practice of wearing a mask during this COVID-19 precaution. In other words, there were questions whether or not the researcher's pronunciation was clearly audible, and whether or not the children who wore a mask were feeling comfortable whilst listening to the story.

\section{Parent's evaluation of the project}

A questionnaire containing 15 items of 3 evaluation areas: content, English vocabulary and the element of entertainment of the stories was distributed to the parents after they had observed the intervention. Parents were asked to evaluate all five stories and to provide feedback for improvement. The results indicate nine parents' satisfaction at a high level, with a mean score of 3.5 from 4 . Parents clearly addressed an advantage if the stories were to be recorded and broadcast in online media, making them available for children regardless of the classroom sessions. This would enable children to learn at home by themselves and more likely with the parents' guidance, which would benefit the family in saving the expense of the child's extra learning. 
Despite the children's difficulty in pronunciation of English words during the intervention, both parents and children had a positive response to the storytelling tool and the teaching methods. An informal interview with the parents revealed their confidence in pronouncing the target words and their readiness in supporting their child's learning. As family involvement with the child's education is considered crucial (Fantuzzo, Tighe \& Childs 2000), the COVID-19 pandemic and its disruption of normal lifestyle has urged all families to take role in child education at home.

As it turned out, these parents liked the project very much and appreciated the university's social engagement activity. Having realised the benefits, they would want to continue telling the stories to their child and enhance English development in childhood. Table 5 summarises the satisfaction level towards the stories as evaluated by the parents.

\section{Content}

Parents strongly agreed that the content was interesting and could appeal to children's attention, as the average score was $3.72(3.50-4.00=$ high $)$. All parents believed that each story had relevant content and could enhance their child's vocabulary development whilst listening to the story. A study by Saracho and Spodek (2010) suggested modern fiction as the most popular choice, the content in these stories may have fit the needs as they were written in contemporary fiction style and content is up-to-date. It was also agreed that the stories were well balanced between world knowledge (Ellis \& Brewster 2014) and skill training, such as encouraging children to solve real-world problems by themselves.

\section{Vocabulary}

The survey reveals parents' positive view about the vocabulary included in the stories. Those words are seen as useful for everyday life. This is, in fact, the strongest point of the study as all parents marked the full score, resulting in the average of 4.00 or the full point, and reflecting words were appropriately chosen for the age group. Attesting the importance of English vocabulary to children, most parents urged for expansion of vocabulary size for their children as it is essential for literacy development (Lee 2011).

\section{Element of entertainment}

Amongst all elements in the story, the entertainment element received the lowest point $(3.59 / 4)$. This could be interpreted to mean that the parents would wish the story to be more entertaining for the children. From personal conversations with the parents, the researcher learned that the entertainment of the stories would attract children and engage them in

TABLE 5: Parents' evaluation of the stories.

\begin{tabular}{lcc}
\hline Story evaluation criteria & Mean score (4.00) & Level of satisfaction \\
\hline Content & 3.72 & High \\
Vocabulary & 4.00 & High \\
Element of entertainment & 3.59 & High \\
\hline Average & $\mathbf{3 . 7 7}$ & High \\
\hline
\end{tabular}

listening and hence accommodate the learning of new words. Comments included suggestions for improvement by putting more weight on fun factors and not just educational content.

\section{Other observed learning behaviours}

The observation notes record the child's behaviour before, during and after listening to the story. This elicits an overview of preschool children's behaviour and their learning process whilst joining storytelling activity.

Personal experience and school background clearly influenced the children's learning behaviours and skills development. Individuals develop at different rates. Their development reflects the typical characteristics and developmental stages in their age group (WHO 2020). For instance, a 3-year-old preschooler still develops skills to collaborate with others whilst a 4-year-old would have passed that stage (Medlineplus 2020) and hence feel more comfortable working with others. In brief, age matters when an individual's ability to develop problem-solving skills and acquire vocabulary from the storytelling activity is concerned. That also helps to explain why some younger children were talking and not paying attention or keeping quiet whilst the older ones were highly engaged in the session and learned new words, as observed during the intervention.

Concerning phonological practice, six children showed little confidence in speaking up or saying the words aloud. This may be a result of their unfamiliarity with English, or simply their shyness leading them to speak fewer utterance, which is a rather common behaviour amongst Thai children. However, as Spere et al. (2008) posited that shyness does not affect vocabulary development or linguistic competence (Society for Research in Child Development 2014), the results of preschoolers' vocabulary test in present study tend to go in line with that. This point about shyness may be worth investigating in future research.

Lastly and predictably, the children's interest level seemed to decline after listening to three stories. Preschoolers became inattentive after $12-15 \mathrm{~min}$. This is normal, especially when they are not taking control of the activity (Moyer \& Von Haller Gilmer 1954). Therefore, it is advisable that only one or two stories are told in a session.

On further examination of individual's behaviours, Child C, aged 3, improved his scores significantly (from 3 in the pretest to 9 in the post-test) even though he did not appear as enthusiastic at the beginning, nor did he achieve as high a score as others. On the contrary, Child H, aged 3, without prior experience of English learning, showed keen interest. He paid great attention to the stories and word pronunciation, resulting in his high score in the post-listening test (13/15). Similarly, Child I, aged 3, received a total of 13 points, but with his decreased attention resulted in the need to hear the stories and words for more times. Thus, the observation 
might draw a confirmation to our common belief that willingness to learn and motivation would likely bring about a learner's better performance.

\section{Implications}

The present study explores possibility of creating home literacy environment, which is said as one of the predictors of children's language development (Puglisi et al. 2017). In this case, storytelling was introduced as an activity that parents could perform to enhance English vocabulary knowledge. However, as parents' language and phonological skills are likely to suggest a child's language skills (Puglisi et al. 2017), the intervention was given to the preschoolers in the presence of the parent, thus enabling them to make use of the material by themselves later on. Family involvement with the child's literacy gave positive results whilst the design was wellresponded during the family confinement because of the measures to curb the spread of COVID-19.

Not only were positive attitudes towards the use of storytelling with children noted, but the study also found positive learning outcomes for vocabulary knowledge development amongst preschoolers. The increased score of the post-listening test from 8.00 to 12.20 (out of 15) may not be considerably significant, but it gives a guideline that storytelling could be implemented at home and performed by parents to promote English learning. These participants learned words used in context, pronounced them and recognised them after the session. As part of the design, a copy of the story scripts with English pronunciation notes was given to each family for future use to enrich the family's home literacy environment (Silinskas et al. 2020).

Whilst paying more attention to the story, the older children in the study achieved a higher score, indicating superiority in word recognition. However, this cannot be generalised as the study was conducted with a small number of subjects and various factors could have influenced the learning outcome, such as the children's background knowledge, the storytelling techniques used and the learning environment. For example, as children were wearing face mask to prevent infection during the intervention, the older children might be better adjusted to the uneased feeling of putting on mask.

With a particular focus on the performance, the findings mirror the different performance and language development between children of different ages. That is, a 5-year-old child remarkably outperformed a 3-year-old child. Although this does not come as a surprise, it does signal the needs to clearly define the age group with a language lesson and the choice of materials used.

As the stories were told in Thai and English words were contextually inserted as extra input, the target words must be carefully chosen to smoothly deliver the necessary meaning and to result in achievable learning outcome (Ellis \& Brewster
2014). For instance, it is advisable that the word connects to the storyline.

In addition, it should be borne in mind that a child aged 3 may be introduced to just one or two words at a time. Each word should be of just one syllable in the plainest form, such as 'cat' and 'bin', and should be well-explained (Collins 2010; Vaahtoranta et al. 2019). Likewise, the word pronunciation must be simple and involve just basic vocal organs (Ellis \& Brewster 2014). It is suggested that three new words for a story should be the right amount and not too overwhelming for the child. However, the storyteller should recall words previously learned in another story to strengthen the child's vocabulary bank.

A follow-up with a high performing child revealed his or her opportunities to attend extra classes thus, being more exposed to English practice. In this case, a family's financial means seems to play a significant role.

In all cases, it was observed that all children could better remember the new words when it was associated with a picture. This seems in line with other studies in implying that concrete words be used with very young learners as they have not yet developed knowledge of abstract items (Cameron 2001; Kara \& Eveyik-Aydin 2019). As reported, the young children matched the correct picture to the word 'butterfly' in the post-test as they could make a clearer mental note of the word when linked with the picture. However, contradicting our prior belief that fantastical images could communicate better with young children, Flack and Horst (2017) suggested a realistic image would be best for the child. An extensive review of using pictures to accommodate children's vocabulary acquisition emphasises the need to use pictures when teaching young children (Strouse, Nyhout \& Ganea 2018).

One unquestionable contribution that the study has made was its utility as a supplementary vocabulary learning method, especially whilst lockdown measures were imposed during the COVID-19 pandemic. Storytelling at home compensated the absence of formal school education and opened up the children's minds to imagination and creativity, as Phillips (2000) suggested. The engaging activity delivers English words to the children in a vivid and clear context of storylines (Ellis \& Brewster 2014), thus enhancing language development.

As an education philosophy has held that collaboration between home and school is crucial for children's achievement of learning outcome, this study has involved the parents in story-based work. The parents keep pace with the child's learning process and complete the learning loop. In other words, the lockdowns ironically allowed the family members to learn together, particularly with the provision of the printed scripts in this study. Once the parents are given useful materials and introduced to the teaching method like storytelling, they could conduct the activity by themselves 
because learning never ceases. The fact that storytelling is one of humanity's inner needs, and a basic mode of communication would make the activity possible, with or without school. In addition, because the world in new normal after COVID-19 pandemic has implied the need to alter our way of life, this present study maintains that literacy development relies more on family than school. Storytelling can be effectively employed as activity for preschoolers, given that the following guidelines emerged from the findings and previous studies:

- the story must be entertaining and engaging

- the length of 300-400 words can keep the students' interest

- no more than three English words should be introduced in each story

- for effective learning outcome, only one to two stories should be told per session. Otherwise, children would be too tired to focus

- a story should be told three times before preschoolers remember the target words

- using meaning in context facilitates vocabulary learning

- words with one syllable are more manageable for the children

- nouns seem easier for preschoolers to remember than verbs or adjectives.

\section{Conclusion}

In conclusion, we have evidenced that the storytelling activity has contributed greatly to the development of children's knowledge whilst it keeps children's interest in learning English vocabulary through stories at the same time. The positive responses from most participants indicating that they could let their imagination flow with the stories were not surprising as previous studies have clearly stated storytelling as a creativity-promoting activity, which children enjoy. This mini-study employed during the COVID-19 pandemic nationwide lockdowns clearly reaffirms that storytelling remains an effective language teaching method and yields the suggested guidelines for utilising storytelling as a learning supplement.

\section{Limitations}

This study appears to have a limitation in sample size because of the difficulty in human contact imposed by measures against the prevalence of the COVID-19. Despite the hardship, data were collected and interpreted as guidelines for storytelling implementation for early childhood learners with almost a zero background in English.

\section{Suggestions for future studies}

As the study was conducted in a short period of time, and the post-test was completed right after the lesson, the children's memory was still fresh. It will be interesting to compare the results if their retention is checked days or weeks after the lesson. Also, a follow-up activity to consolidate the acquired vocabulary will promote better learning outcomes.
Concerning the population size, a future study may consider working on a homogeneous group of 20-30 participants in order to identify their learning patterns. For a future sustainable project, one might see the importance of including a systematic pronunciation training for parents. As pronunciation difficulty is prone to mitigate the ability of Thai learners of English, prior training may minimise this challenge. Lastly, for language learning material development, in-house stories may appear novel, but they risk a lack of entertainment and probably a cross-cultural element, which is important for this globalised world. Extra effort to ensure that entertaining elements are inserted is recommended and using stories from other cultures may also expand the children's knowledge horizon.

\section{Acknowledgements}

The study was a collaboration between the B.A. in English Programme and the Center for Academic Services at Walailak University under the social engagement scheme to benefit the community. The authors thank the parents and the preschoolers who kindly attended the programme despite the confusion and restriction the COVID-19 had brought. The authors also highly appreciate the Institute of Research and Innovation, Walailak University, for the supports and facilities throughout the research and the reviewers for their insightful comments that helped to improve the article. Storytelling - an alternative delivery of English vocabulary for preschoolers during COVID-19's lockdown.

\section{Competing interests}

The authors have declared that no competing interests exist.

\section{Authors' contributions}

A.K. and W.W. contributed to the design and implementation of the research, to the analysis of the results and to the writing of the manuscript.

\section{Funding information}

This research received no specific grant from any funding agency in the public, commercial or not-for-profit sectors.

\section{Data availability statement}

The involvement of children and parents in this study was done with total observance of informed consent and high confidentiality of the information maintained. The researcher explained to parents and children the methodology, effects and benefits in detail with accompanied documents. If agreed, parents then provided informed consent for their child to be involved.

\section{Disclaimer}

The views and opinion expressed in this article are those of the authors and do not necessarily reflect the official policy or position of any affiliated agency of the authors. 


\section{References}

Al Zoubi, S.M., 2018, 'The impact of exposure to English language on language acquisition', Journal of Applied Linguistics and Language Research 5(4), 151-162, viewed 26 September 2020, from www.jallr.com.

Balakrishnan, V. \& Thambu, N., 2017, 'Using moral and ethical stories to inculcate values among preschoolers', International Journal for Studies on Children, Women, Elderly and Disabled 2(6), 8-15.

Bunparit, C., 2014, 'Using English tales in EFL classrooms', Songklanakarin: E-Journa of Social Sciences \& Humanities 20(1), 185-201.

Cameron, L., 2001, Teaching languages to young learners, Cambridge Language Teaching Library, Cambridge University Press, Cambridge. https://doi. org/10.1017/CBO9780511733109

Childers, J.B. \& Tomasello, M., 2006, 'Are nouns easier to learn than verbs?', in K. Hirsh-Pasek \& R.M. Golinkoff (eds.), Three experimental studies. Action meets word: How children learn verbs, pp. 311-335, Oxford University Press, Oxford.

Collins, M.F., 2010, 'ELL preschoolers' English vocabulary acquisition from storybook reading', Early Childhood Research Quarterly 25(1), 84-97. https://doi. reading, Early Childhood Rese
org/10.1016/j.ecresq.2009.07.009

Cook, V., 2019, 'Challenging hidden assumptions in language teaching', LEARN Journal: Language Education and Acquisition Research Network Journal 12(1), 30-37.

Ellis, G. \& Brewster, J., 2014, Tell it again! The storytelling handbook for primary English language teachers, Teaching English series, British Council, viewed 30 May 2020, from https://www.teachingenglish.org.uk/sites/teacheng/files/pub_ D467_Storytelling_handbook_FINAL_web.pdf.

Farkas, C., Santelices, M.P., Vallotton, C.D., Brophy-Herb, H.E., Iglesias, M., Sieverson, C. et al., 2020, 'Children's storybooks as a source of mental state references: Comparison between books from Chile, Colombia, Scotland and USA', Cognitive Development 53, 100845. https://doi.org/10.1016/j.cogdev.2019.100845

Fantuzzo, J., Tighe, E. \& Childs, S., 2000, 'Family Involvement Questionnaire: A multivariate assessment of family participation in early childhood education', Journal of Educational Psychology 92(2), 367-376. https://doi.org/10.1037/0022-0663.92.2.367

Flack, Z.M. \& Horst, J.S., 2018, 'Two sides to every story: Children learn words bette from one storybook page at a time', Infant and Child Development 27(1), e2047. https://doi.org/10.1002/icd.2047

Friday, M.J., 2015, How storytelling inspires children to learn English, viewed 30 May 2020, from https://www.kurzweiledu.com/blog/2015/how-storytelling-inspireschildren-learn-english.html.

Gallets, M.P., 2005, 'Storytelling and story reading: A comparison of effects on children's memory and story comprehension', Electronic Theses and Dissertations. Paper 1023, viewed 19 September 2020, from https://dc.etsu.edu/etd/1023.

Imsri, P., 2015, 'Using YouTube to engage learners in pronunciation practice', in S. Panplum (ed.), Proceedings of Symposiums of International Languages and Knowledge, pp. 206-209, Walailak University Press, Nakhon Sri Thammarat.

Kanokpermpoon, M., 2007, 'Thai and English consonantal sounds: A problem or a potential for EFL learning?', ABAC Journal 27(1), 57-66.

Kara, K. \& Eveyik-Aydin, E., 2019, 'Effects of TPRS on very young learners' vocabulary acquisition', Advances in Language and Literary Studies 10(1), 135-146. https:// doi.org/10.7575/aiac.alls.v.10n.1p.135

Kaur, A., Young, D. \& Kirkpatrick, R., 2016, 'English education policy in Thailand: Why the poor results?', in R. Kirkpatrick (ed.), English language education policy in Asia, pp. 345-361, Springer International Publishing, Cham, Switzerland.

Kaiser, A.P. \& Hancock, T.B., 2003, 'Teaching parents new skills to support their young children's development', Infants \& Young Children 16(1), 9-21, viewed 19 children's development', Infants \& Young Children 16(1), 9-21, viewed
September 2020, from https://depts.washington.edu/isei/iyc/kaiser_16_1.pdf.

Kirsch, C., 2012, 'Using storytelling to teach vocabulary in language lessons: Does it work?', The Language Learning Journal 44(1), 33-51. https://doi.org/10.1080/09 571736.2012.733404

Lee, J., 2011, 'Size matters: Early vocabulary as a predictor of language and literacy competence', Applied Psycholinguistics 32(1), 69-92. https://doi.org/10.1017/ S0142716410000299

Lowry, L., 2016, Verbs pave the way for language development, The Hanen Center. CHanen Early Language Program, viewed 26 September 2020, from http://www. hanen.org/Helpful-Info/Articles/Verbs-Pave-the-Way-for-LanguageDevelopment.aspx.

Lugmayr, A., Sutinen, E., Suhonen, J., Sedano, C.I., Hlavacs, H. \& Montero, C.S., 2017, 'Serious storytelling: A first definition and review', Multimedia Tools and Applications 76(14), 15707-15733. https://doi.org/10.1007/s11042-016-3865-5

McKeough, A., Bird, S., Tourigny, E., Romaine, A., Graham, S., Ottmann, J. et al., 2008 'Storytelling as a foundation to literacy development for aboriginal children: Culturally and developmentally appropriate practices', Canadian Psychology 49(2), 148-154. https://doi.org/10.1037/0708-5591.49.2.148

Medlineplus, 2020, Preschooler development, viewed 26 September 2020, from https://medlineplus.gov/ency/article/002013.htm.

Moyer, K. \& Von Haller, G.B., 1954, 'The concept of attention spans in children', The Elementary School Journal 54(8), 464-466, viewed 27 September 2020, from http://www.jstor.org/stable/998982.

Neuman, S.B. \& Dwyer, J., 2009, 'Missing in action: Vocabulary instruction in Pre-k', The Reading Teacher 62(5), 384-392. https://doi.org/10.1598/RT.62.5.2

Neuman, S.B. \& Wright, T.S., 2019, 'The magic of words: Teaching vocabulary in the early childhood classroom', American Educator 38(2), 4-13.
NIETS, n.d., 'A summary of ONET results of 2019', viewed 27 June 2020, from http:// www.newonetresult.niets.or.th/AnnouncementWeb/PDF/SummaryONETP6 2562. pdf.

Noomura, S., 2013, 'English-teaching problems in Thailand and Thai teachers' professional development needs', English Language Teaching 6(11), 139-147. https://doi.org/10.5539/elt.v6n11p139

Phillips, L., 2000, 'Storytelling: The seeds of children's creativity', Australasian Journa of Early Childhood 25(3), 1-5. https://doi.org/10.1177/183693910002500302

Puglisi, M.L., Hulme, C., Hamilton, L.G. \& Snowling, M.J., 2017, 'The home literacy environment is a correlate, but perhaps not a cause, of variations in children's language and literacy development', Scientific Studies of Reading 21(6), 498-514. https://doi.org/10.1080/10888438.2017.1346660

Robin, B., 2008, 'Digital Storytelling: A Powerful Technology Tool for the 21st Century Classroom', Theory Into Practice 47(3), 220-228. https://doi.org/10.1080/ 00405840802153916

Roney, R.C., 1996, 'Storytelling in the classroom: Some theoretical thoughts', Storytelling World 9, 7-9.

Roskos, K., Burstein, K. \& Sullivan, S., 2013, 'A small-scale study of the effects of supplemental vocabulary instruction on preschoolers with vocabulary delays',
Creative Education 4(7A), 15-22. https://doi.org/10.4236/ce.2013.47A1003

Saracho, O.N. \& Spodek, B., 2010, 'Families' selection of children's literature books', Early Childhood Education Journal 37(5), 401-409. https://doi.org/10.1007/ s10643-009-0365-5

Schaefer, M. \& Kotzé, J., 2019, 'Early reading skills related to Grade 1 English Second Language literacy in rural South African schools', South African Journal of Childhood Education 9(1), a644. https://doi.org/10.4102/sajce.v9i1.644

Shi, T., 2018, 'A study of the TPR method in the teaching of English to primary schoo students', Theory and Practice in Language Studies 8(8), 1087-1093. https://doi. org/10.17507/tpls.0808.25

Sibanda, R. \& Kajee, L., 2019, 'Home as a primary space: Exploring out-of-school literacy practices in early childhood education in a township in South Africa', South African Journal of Childhood Education 9(1), a686. https://doi.org/10.4102/sajce.v9i1.686

Silinskas, G., Sénéchal, M., Torppa, M. \& Lerkkanen, M., 2020, 'Home literacy activities and children's reading skills, independent reading, and interest in literacy activities from kindergarten to Grade 2', Frontiers in Psychology 11, 1508. https://doi. org/10.3389/fpsyg.2020.01508

Society for Research in Child Development, 2014, 'Shy kids not delayed or deficient in language, they just speak less', Science Daily, February 3, viewed 27 September 2020, from www.sciencedaily.com/releases/2014/02/140203084236.htm.

Soommanus, P. \& Musikaphan, W., 2019, 'Activities supporting moral behavior by using story-based for early childhood in child development centers, Ranong province', Kasetsart Educational Review 34(3), 61-70.

Spere, K., Evans, M., Hendry, C. \& Mansell, J., 2008, 'Language skill in shy and non-shy preschoolers and the effect of context', Journal of Child Language 36(1), 53-71. https://doi.org/10.1017/S0305000908008842

Srihasarn, G. \& Wuttipornpong, T., 2013, 'Using storytelling to facilitate L2 vocabulary learning and retention: A case study of a secondary school in Thailand', Journal of Liberal Arts, Ubon Ratchathani University 9(2), 283-315.

Strouse, G.A., Nyhout, A. \& Ganea, P.A., 2018, 'The role of book features in young children's transfer of information from picture books to real-world contexts' Frontiers in Psychology 9, 50. https://doi.org/10.3389/fpsyg.2018.00050

Sunyakul, N. \& Teo, A., 2020, 'Primary school English teachers' application of knowledge/skills from boot camp to their classroom teaching practices and factors hindering their application', LEARN Journal: Language Education and Acquisition Research Network Journal 13(1), 145-160.

Thanompongchart, P., 2019, The development of English achievements and moral of Grade 4 and 5 students by using Aesop's fables and the Cornell note taking method, Faculty of Education, Chulalongkorn University, viewed 03 June 2020 from https://cuir.car.chula.ac.th/xmlui/handle/123456789/62950.

Uysal, N.D. \& Yavuz, F., 2015, 'Teaching English to very young learners', 7th World Conference on Educational Sciences, (WCES-2015), 05-07 February 2015, Novotel Athens Convention Center, Athens, Greece, Procedia - Social and Behavioral Sciences 197, 19-22, viewed 27 June 2020, from https://www.academia. edu/4514739/Teaching_English_to_Young_Learners_How_They_Learn_and_ the_Pedagogical_Implication.

Vaahtoranta, E., Lenhart, J., Suggate, S. \& Lenhard, W., 2019, 'Interactive elaborative storytelling: Engaging children as storytellers to foster vocabulary', Frontiers in Psychology 10, 1534. https://doi.org/10.3389/fpsyg.2019.01534

Vaahtoranta, E., Suggate, S., Jachmann, C., Lenhart, J. \& Lenhard, W., 2018 'Can explaining less be more? Enhancing vocabulary through explicit versus
elaborative storytelling', First Language 38(2), 198-217. https://doi.org/10.1177/ elaborative storytellin', 0142723717737452

Vilà-Giménez, I., Igualada, A. \& Prieto, P., 2019, 'Observing storytellers who use rhythmic beat gestures improves children's narrative discourse performance' Developmental Psychology 55(2), 250-262. https://doi.org/10.1037/dev0000604

WHO, 2020, Improving early childhood development: Who guideline, viewed 26 September 2020, from https://www.who.int/maternal child adolescent/child/ Improving_Early_Childhood_Development_WHO_Guideline_Summary_.pdf.

Wilkins, D.A., 1972, Linguistics in language teaching, Edward Arnold, London.

Wright, A., 1989, Pictures for language learning, Cambridge University Press, Cambridge. Xiaofei, H. \& Modehiran, P., 2019, 'Vocabulary teaching using picture storytelling to improve English vocabulary knowledge of grade 7 Thai students', An Online Journal of Education 14(2), OJED1402018, 1-13, viewed 27 September 2020, from https://so01.tci-thaijo.org/index.php/OJED/article/view/191470. 